\title{
Emerging obesity and dietary habits among James Bay Cree youth
}

\section{Cynthia Bou Khalil, Louise Johnson-Down and Grace M Egeland*}

School of Dietetics and Human Nutrition and Centre for Indigenous Peoples' Nutrition and Environment (CINE), McGill University, Macdonald Campus, 21,111 Lakeshore Road, Ste Anne de Bellevue, H9X 3V9, Québec, Canada

Submitted 20 April 2009: Accepted 20 January 2010: First published online 15 April 2010

\begin{abstract}
Objective: To describe dietary habits and extent of overweight and obesity among Cree youth.

Design: Dietary intake and habits were assessed by a $24 \mathrm{~h}$ recall and FFQ as part of a cross-sectional survey.

Setting: Three Cree communities in northern Québec, Canada.

Subjects: A total of 125 youth aged 9-18 years.

Results: Overall $67 \cdot 6 \%$ of the study population was either at risk of overweight or overweight. Over $98 \%$ had a usual saturated fat intake over $10 \%$ of energy while $65 \%$ had a lower consumption of fruit/vegetables and $95 \%$ had a lower consumption of milk and milk products than recommended by Canada's Food Guide. The majority $(96 \cdot 8 \%)$ consumed high-fat foods ( $>40 \%$ of total energy as fat), which accounted for $39 \%$ of total energy intake (EI). Similarly, $92 \cdot 8 \%$ consumed high-sugar food and beverages ( $>25 \%$ of total energy as sugar), which accounted for $12 \cdot 8 \%$ of total EI. Furthermore, $95 \%$ of the youth had a Healthy Eating Index (HEI) below the recommended score of 80 or above. Certain measures of diet quality (traditional food (TF) consumption, HEI and vegetables and fruit consumption) were significantly correlated with adiposity measures.

Conclusions: A high prevalence of low-diet quality was found with a high degree of sugar and fat intake and a low consumption of vegetables/fruit and milk/milk alternates and any weekly TF. Dietary interventions are sorely needed.
\end{abstract}

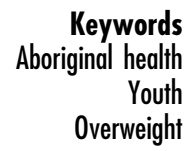

Overweight and obesity are steadily increasing among adults as well as children and youth with consequences for increased risk of type 2 diabetes mellitus (DM), hypertension, heart disease and all-cause mortality ${ }^{(1-4)}$. Early detection, prevention and treatment of obesity will avoid consequences later in life ${ }^{(3)}$. Indigenous peoples in Canada show high rates of obesity. In the Canadian Community Health Survey conducted in 2004 in all provinces but not in the territories, $41 \%$ of off-reserve indigenous children aged 2-17 years were either at risk for overweight (21\%; BMI $>85$ th percentile) or overweight (20\%; BMI >95th percentile) - a greater prevalence than seen for other ethnic groups of similarly aged children in Canada in which $26 \%$ of Whites, $29 \%$ of Blacks and $18 \%$ of South-east/East Asians were at risk for overweight or overweight $^{(4)}$.

Indigenous peoples in Canada continue to undergo a nutrition transition with several studies reporting younger generations consuming less traditional food (TF) than older generations $^{(5,6)}$. TF contributed to only $4 \cdot 5 \%$ of total energy intake (EI) in Dene/Métis of the Canadian Northwest
Territory and Canadian Yukon Territory First Nations children aged 10-12 years ${ }^{(7)}$. The shift towards a diet nearly exclusively from market food is accompanied by an increase in energy, refined carbohydrates, fat and saturated fat in the diet ${ }^{(5,8,9)}$. Fruit and vegetables as well as grains and meat contributed to less than half of the EI of Dene/ Métis and Yukon First Nations children, whereas 55\% of energy came from sweets, mixed dishes and total fat with a high intake of high-fat foods noted ${ }^{(7)}$. In a study of Cree youth ( $\geq 9$ years of age), conducted in two James Bay communities in northern Québec, Canada, those with a BMI of $>90$ th percentile consumed statistically significantly less milk and milk products and fruit and vegetables than did youth with a lower $\mathrm{BMI}^{(10)}$. Dietary changes have a major role in the development of obesity and type $2 \mathrm{DM}$ in many North American indigenous communities ${ }^{(11,12)}$.

The traditional diet of Cree, the largest First Nations group in North America, was based mainly on hunting and fishing: it was a diet rich in protein, moderate in fat and low in carbohydrates. Historically, the Cree were considered to have high EI compensated by a traditional 


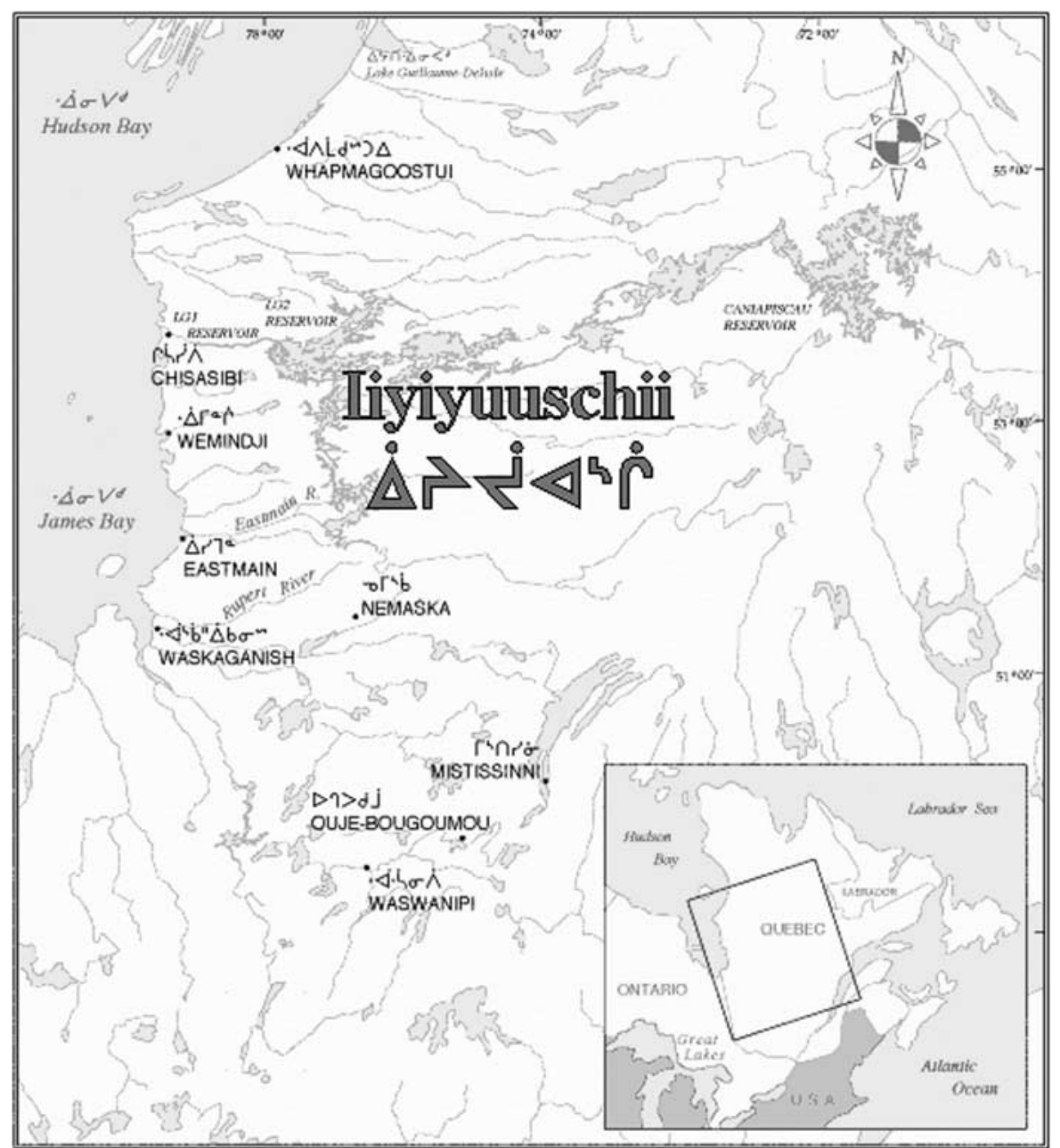

Fig. 1 Map of the James Bay Cree Communities situated in northern Québec, Canada. The small box to the right depicts the location of Québec in relation to north-eastern United States

active lifestyle along with cold weather and seasonal food shortages $^{(13)}$. There are eight distinct Cree groups, of which the James Bay Cree (Iiyiyiuch) group of northern Québec was the focus of the present study. In the last 30 years, the Cree of northern Québec, situated in nine communities of the James Bay Region (Fig. 1), have been affected by many socio-cultural and political changes such as large development projects ${ }^{(13)}$ along with a shift away from hunting and harvesting activities with increased reliance on store-bought foods - all having major implications for the Cree communities. The Cree now suffer from obesity, hypertension and type $2 \mathrm{DM}$, which was not the case in the past ${ }^{(14)}$. As of 2001, 56-62\% of children were estimated to be at risk of overweight in the nine James Bay Cree Communities ${ }^{(13)}$. The present study was undertaken to evaluate dietary habits of youth in three Cree communities of James Bay in order to guide interventions. Furthermore, it was hypothesised that those at risk for overweight or overweight would have poorer dietary characteristics and would consume less TF than normalweight individuals.

\section{Materials and methods}

\section{Study population and design}

The study involved James Bay, Québec Cree youth. A health survey was conducted in three of the nine Cree communities: Mistissini, Wemindji and Eastmain, which account for 3200, 1267 and 550 residents, respectively, and from which 300, 200 and 150 Cree, respectively, were randomly selected. The present study is restricted to youth aged 9-18 years, of whom 198 were randomly selected from the three communities, with 125 youth participating providing an overall $63.2 \%$ participation rate. A higher participation rate $(71 \cdot 3 \%)$ was noted among the 8-14-year-olds. The sample size provided $80 \%$ power to detect a prevalence of weekly consumption of TF of $50 \%(95 \%$ CI $44 \cdot 5,55 \cdot 5)$.

Ethics approval was obtained by the Research Ethics Boards of McGill, Laval and McMaster Universities as well as the Research Committee of the Cree Board of Health and Social Services of James Bay. The Cree Board of Health coordinated the planning and field logistics. 


\section{Data collection}

Data were collected in Mistissini during the summer of 2005 and in Wemindji and Eastmain in June and August 2007. A research team included members from McGill University (Centre for Indigenous Peoples' Nutrition and Environment), Laval University, McMaster University and the Cree Board of Health. Bilingual community members were trained to conduct interviews and recruit participants.

Individual and parental consent were obtained. Anthropometric measures were taken without shoes and in normal clothing by trained nurses. Height was measured in centimetres using a graduated tape with the patient standing barefoot on a hard surface. Waist was measured at the end of exhalation with the tape horizontally located between the last floating rib and the iliac crest. BMI $\left(\mathrm{kg} / \mathrm{m}^{2}\right)$ was calculated after subtracting $0.85 \mathrm{~kg}$ for clothing weight. Body weight and fat percentage were determined using a foot-to-foot bioelectrical impedance instrument (Tanita Corp, Arlington Heights, IL, USA).

Two qualitative market and traditional FFQ were administered. The traditional FFQ included an exhaustive list of all TF obtained through hunters and trappers and discussions with community representatives. The market FFQ was designed to capture usual beverages and indicators of high-sugar and high-fat food items purchased at local establishments. All questionnaires were checked by quality control staff. The traditional FFQ includes animals such as the caribou and moose, birds such as the ptarmigan, and fish and seasonal variation in intake.

Dietary intake was assessed by a $24 \mathrm{~h}$ recall using graduated food models of food portion sizes (Santé Québec, Montréal, Canada) with repeat recalls on 20\% of participants. The recall used a five-step data collection technique, which included a quick list, forgotten foods, details and probing, review and finally a question about vitamin and mineral supplements.

Twenty-four-hour recalls were entered into the CANDAT software (2007; Godin, London, Ontario, Canada) and double verified for accuracy. Nutrient intakes were obtained using the Canadian Nutrient File 2007b (2007; Health Canada, Ottawa, Ontario, Canada) and a file with 2000 additional foods derived from food labels and standardised recipes. Data from the FFQ were entered into Epi-Info (US Centers for Disease Control and Prevention (CDC), Atlanta, GA, USA). Dietary intakes were compared with Canada's Food Guide for First Nations, Inuit and Métis, which is similar to the Canadian Food Guide but tailored to respect indigenous food traditions.

In addition, a Canadian modification to the Healthy Eating Index (HEI) was adapted to the current age group and used to assess diet quality, where a score of $\geq 80$ indicates a healthy eating pattern ${ }^{(15)}$.

CDC guidelines of age- and gender-specific BMI percentiles were used to categorise participants 'at-risk of overweight' (BMI $\geq 85$ th and $<95$ th percentile) or 'overweight' $\left(\right.$ BMI $\geq 95$ th percentile) ${ }^{(16)}$. Estimation of the distribution of waist circumference (WC) was based on WC percentiles of children and adolescents from the Third National Health and Nutrition Examination Survey ${ }^{(17)}$ where $\geq 85$ th percentile was the cut-off to define high central adiposity. Having a body fat percentage $\geq 75$ th percentile was the cut-off used to categorise youth into a high body fat group based upon a Caucasian population ${ }^{(18)}$.

High-sugar foods were defined as those foods containing $>25 \%$ of energy as total sugar and included highsugar cereals, cookies, fruit punches and soft drinks. Nutrient-rich foods such as fruit and vegetables were excluded from the list of high-sugar foods. High-fat foods were defined as those with $>40 \%$ of energy as total fat and included high-fat baked goods, cookies, mixed meals, TF as well as dressings and spreads.

To calculate the potential under-reporting of dietary intake, we calculated the ratio of reported EI to BMR based on age and gender and methods described elsewhere, where a value below 1.5 was used to identify underreporting ${ }^{(19-21)}$. TF intake was categorised into two groups, infrequent (less than one time per week) and weekly consumption (at least one time per week).

Statistical analyses were run using the SAS for Windows statistical software package version 9·1 (SAS Institute Inc., Cary, NC, USA). Analyses were conducted with and without the under-reporters of EI, but as the results from these analyses were similar, they are reported for the total sample. The percentage of consumed saturated fat $>10 \%$ of total energy was adjusted for usual intake using the repeat recall ${ }^{(22)}$ and adjustments were calculated using the Iowa State Software for Intake Distribution Estimate (1996; Iowa State University, Ames, IA, USA).

Rate ratios and 95\% CI were calculated to evaluate risk of overweight and of having a high WC by TF consumption and other dietary habits.

\section{Results}

The study group consisted of an equal proportion of boys ( $n$ 61) and girls ( $n$ 64). The mean age of the participants was $13 \cdot 2$ ( $\mathrm{SD} 2 \cdot 8$ ) years and the average BMI percentile was $83 \cdot 5$, approaching the 85 th percentile for being 'at risk of overweight' (Table 1). Youth were separated into two age groups: 9-13 and 14-18 years of age. The mean body fat and WC approximated the 82nd and 85th percentiles, respectively, and did not differ by age groups. The mean body fat percentile (94.6) was significantly higher $(P \leq 0.005)$ among girls than boys (Table 1$)$. Overall, $67 \cdot 6 \%$ of the participants were either at risk for overweight or overweight. Moreover, $81 \cdot 6 \%$ of the participants fell above the cut-off value for an at-risk WC.

The mean EI:BMR ratio in the present study was $1 \cdot 31$ (sD 0.62), which suggests an overall population with mild under-reporting of energy. No difference in the EI:BMR ratio among age groups or genders was observed. 
Table 1 Summary of anthropometric characteristics by gender and age, Cree youth of three communities (2005-2007)

\begin{tabular}{|c|c|c|c|c|c|c|c|c|c|c|}
\hline & \multicolumn{4}{|c|}{ Age group (years) } & \multicolumn{4}{|c|}{ Gender } & & \\
\hline & \multicolumn{2}{|c|}{$9-13(n 68)$} & \multicolumn{2}{|c|}{$14-18(n 57)$} & \multicolumn{2}{|c|}{ Girls $(n 64)$} & \multicolumn{2}{|c|}{ Boys ( $n$ 61) } & \multicolumn{2}{|c|}{ Total $(n 125)$} \\
\hline & Mean or \% & SD & Mean or $\%$ & SD & Mean or \% & SD & Mean or \% & SD & Mean or \% & SD \\
\hline Height $(\mathrm{cm})$ & $155 \cdot 6$ & $10 \cdot 7$ & $170 \cdot 8^{\star \star}$ & $6 \cdot 8$ & $159 \cdot 3$ & $9 \cdot 6$ & $165 \cdot 9^{*}$ & $13 \cdot 1$ & $162 \cdot 5$ & $11 \cdot 9$ \\
\hline Weight (kg) & $60 \cdot 4$ & $20 \cdot 2$ & $79 \cdot 4^{\star *}$ & $20 \cdot 1$ & $67 \cdot 5$ & $23 \cdot 1$ & $70 \cdot 5$ & $21 \cdot 4$ & $68 \cdot 9$ & $22 \cdot 2$ \\
\hline BMI percentile ${ }^{(16)}$ & $84 \cdot 6$ & $20 \cdot 9$ & $82 \cdot 0$ & $20 \cdot 9$ & 83.9 & $20 \cdot 5$ & $83 \cdot 0$ & $21 \cdot 4$ & $83 \cdot 4$ & $20 \cdot 9$ \\
\hline WC percentile ${ }^{(17)}$ & $87 \cdot 9$ & $17 \cdot 3$ & $81 \cdot 3$ & $21 \cdot 7$ & $87 \cdot 6$ & $16 \cdot 6$ & $82 \cdot 0$ & $22 \cdot 2$ & 84.9 & $19 \cdot 6$ \\
\hline Body fat percentile ${ }^{(18)}$ & $81 \cdot 7$ & $30 \cdot 6$ & $83 \cdot 5$ & $25 \cdot 7$ & $94 \cdot 6$ & $28 \cdot 0$ & $84 \cdot 2^{\star \star}$ & $38 \cdot 8$ & $82 \cdot 5$ & $28 \cdot 4$ \\
\hline$\%$ at risk of overweight ${ }^{(16)}$ & $13 \cdot 2$ & & $19 \cdot 3$ & & $6 \cdot 25$ & & $26 \cdot 2$ & & $16 \cdot 0$ & \\
\hline$\%$ overweight ${ }^{(16)}$ & $54 \cdot 4$ & & $38 \cdot 6$ & & $54 \cdot 7$ & & $39 \cdot 3$ & & $47 \cdot 2$ & \\
\hline$\%$ at risk for $W^{(17)}$ & $83 \cdot 8$ & & $79 \cdot 0$ & & $84 \cdot 4$ & & $78 \cdot 7$ & & $81 \cdot \overline{6}$ & \\
\hline
\end{tabular}

WC, waist circumference.

Data are shown as mean and SD unless \% noted.

${ }^{\star} P \leq 0 \cdot 05, t$ test.

${ }^{\star \star} P \leq 0 \cdot 01, t$ test.

Table 2 Past day macronutrient (\% of energy) and high-sugar and high-fat food intake by age group and gender, Cree youth of three communities (2005-2007)

\begin{tabular}{|c|c|c|c|c|c|c|c|c|c|c|}
\hline & \multicolumn{4}{|c|}{ Age category (years) } & \multicolumn{4}{|c|}{ Gender } & \multirow{2}{*}{\multicolumn{2}{|c|}{ Total $(n 125)$}} \\
\hline & \multicolumn{2}{|c|}{$9-13(n 68)$} & \multicolumn{2}{|c|}{$14-18(n 57)$} & \multicolumn{2}{|c|}{ Girls $(n 64)$} & \multicolumn{2}{|c|}{ Boys ( $n$ 61) } & & \\
\hline & Mean or $\%$ & SD & Mean or \% & SD & Mean or \% & SD & Mean or $\%$ & SD & Mean or $\%$ & SD \\
\hline$E(k J)$ & $9246 \cdot 9$ & $3906 \cdot 3$ & $9308 \cdot 1$ & $4621 \cdot 4$ & $8352 \cdot 6$ & $3453 \cdot 7$ & $10244 \cdot 2^{*}$ & $4752 \cdot 4$ & $9274 \cdot 6$ & $4229 \cdot 9$ \\
\hline$\% \mathrm{E}$ as protein & $15 \cdot 1$ & $7 \cdot 1$ & $15 \cdot 7$ & $7 \cdot 1$ & $14 \cdot 0$ & $5 \cdot 6$ & $16 \cdot 9^{\star}$ & $8 \cdot 1$ & $15 \cdot 4$ & $7 \cdot 1$ \\
\hline$\% \mathrm{E}$ as carbohydrates & $51 \cdot 6$ & $12 \cdot 4$ & $48 \cdot 3$ & $14 \cdot 8$ & $52 \cdot 4$ & $12 \cdot 9$ & $47 \cdot 6^{\star}$ & $14 \cdot 0$ & $50 \cdot 1$ & $13 \cdot 6$ \\
\hline$\% \mathrm{E}$ as fat & 33.9 & $9 \cdot 7$ & $36 \cdot 7$ & $10 \cdot 7$ & $34 \cdot 2$ & $9 \cdot 9$ & $36 \cdot 3$ & $10 \cdot 5$ & $35 \cdot 2$ & $10 \cdot 2$ \\
\hline$\% \mathrm{E}$ as saturated fat & $11 \cdot 7$ & $5 \cdot 2$ & $11 \cdot 7$ & $5 \cdot 1$ & $11 \cdot 8$ & $5 \cdot 2$ & $11 \cdot 7$ & $5 \cdot 0$ & $11 \cdot 7$ & $5 \cdot 1$ \\
\hline$\% \mathrm{E}$ as sugar & $16 \cdot 8$ & $11 \cdot 9$ & $13 \cdot 8$ & $11 \cdot 4$ & $16 \cdot 0$ & $11 \cdot 5$ & $14 \cdot 8$ & $12 \cdot 0$ & $14 \cdot 4$ & $11 \cdot 7$ \\
\hline$\% E$ as saturated fat $>10 \%$ & $99 \cdot 2$ & & $98 \cdot 8$ & & $99 \cdot 9$ & & $98 \cdot 8$ & & $98 \cdot 1$ & \\
\hline$\%$ consumed HSFt & $95 \cdot 6$ & & $89 \cdot 5$ & & $95 \cdot 3$ & & $90 \cdot 2$ & & $92 \cdot 8$ & \\
\hline$\% \mathrm{E}$ from HSF among consumers & $13 \cdot 7$ & & $11 \cdot 7$ & & $13 \cdot 7$ & & $11 \cdot 9$ & & $12 \cdot 8$ & \\
\hline$\%$ consumed HFF $\ddagger$ & $98 \cdot 5$ & & $94 \cdot 7$ & & $96 \cdot 9$ & & $96 \cdot 7$ & & $96 \cdot 8$ & \\
\hline$\% \mathrm{E}$ from HFF among consumers & $38 \cdot 8$ & & $40 \cdot 1$ & & $39 \cdot 9$ & & $38 \cdot 7$ & & $39 \cdot 3$ & \\
\hline Canadian Healthy Eating Index ${ }^{(15)}$ & $68 \cdot 1^{*}$ & $8 \cdot 3$ & $60 \cdot 7$ & $9 \cdot 0$ & $64 \cdot 7$ & $7 \cdot 7$ & $64 \cdot 7$ & $10 \cdot 8$ & $64 \cdot 7$ & $9 \cdot 3$ \\
\hline
\end{tabular}

E, energy; HSF, high-sugar food; HFF, high-fat food.

Data are shown as mean and SD unless \% noted.

${ }^{*} P \leq 0 \cdot 05, t$ test for significant differences by gender or age category.

HHSF were defined as those foods containing $>25 \%$ of energy as total sugar and included high-sugar cereals, cookies, fruit punches and soft drinks. ¥HFF were defined as those with $>40 \%$ of energy as total fat and included high-fat baked goods, cookies, mixed meals, traditional foods as well as dressings and spreads.

Youth having a BMI $\geq 85$ th percentile were observed to have a lower mean EI:BMR ratio $(1 \cdot 16$ (SD $0 \cdot 45))$ than their normal-weight counterparts (1.56 (SD 0.45; $P \leq 0 \cdot 01)$ ), indicating a greater under-reporting among at-risk of overweight youth.

Reported EI was not significantly different between age groups, but the mean reported energy and protein intake was significantly higher among the boys. The percentage of energy as carbohydrate was significantly higher among the girls than among the boys (Table 2). Intake of total fat and saturated fat was not significantly different by age or gender. Over $98 \%$ consumed saturated fat above $10 \%$ of total energy based upon intake adjusted for repeat recalls.

In addition, $92 \cdot 8 \%$ of participants reported consuming high-sugar foods, which accounted for $12 \cdot 8 \%$ of total daily EI, whereas $96 \cdot 8 \%$ of the participants were found to consume high-fat foods, which accounted for nearly $40 \%$ of total EI. No significant differences were observed in consumption of high-sugar or high-fat foods by age or gender (Table 2). The Canadian HEI scores were, on average, low among the youth with a mean score of 64.7 (SD 9.3), with $95 \%$ of the youth falling below the recommended score of 80 or above. There were no significant differences in scores between boys and girls, but older youth had significantly lower scores than younger youth (Table 2).

A significantly higher proportion of 9-13-year-olds (48\%) than 14-18-year-olds (32\%) were observed to consume 'baked goods and cereals' (Table 3). However, no difference by age and gender was observed in the consumption of other high-sugar food groups. In addition, the 'baked goods and cereal' group contributed to the highest 
Table 3 Prevalence of consumption and percentage of energy in the past day from high-sugar ( $>25 \%$ total sugars) or high-fat ( $>40 \%$ total fat) food by type of food, age and gender, Cree youth of three communities (2005-2007)

\begin{tabular}{|c|c|c|c|c|c|}
\hline & \multicolumn{2}{|c|}{ Age (years) (\%) } & \multicolumn{2}{|c|}{$\operatorname{Sex}(\%)$} & \multirow{2}{*}{$\begin{array}{c}\text { Total } \\
(n 125)(\%)\end{array}$} \\
\hline & $9-13(n 68)$ & $14-18(n 57)$ & Girls $(n 64)$ & Boys $(n 61)$ & \\
\hline \multicolumn{6}{|l|}{ Consuming high-sugar food groups } \\
\hline Baked goods and cereals & $48 \cdot 5$ & $31 \cdot 6^{*}$ & $40 \cdot 6$ & $41 \cdot 0$ & $40 \cdot 8$ \\
\hline Dressings/sauces/spreads & $29 \cdot 4$ & $38 \cdot 6$ & $26 \cdot 6$ & $41 \cdot 0$ & $33 \cdot 6$ \\
\hline High-sugar drinks including soft drinks & $66 \cdot 2$ & $57 \cdot 9$ & $62 \cdot 5$ & $62 \cdot 3$ & $62 \cdot 4$ \\
\hline Snack foodst & $32 \cdot 3$ & $38 \cdot 6$ & $40 \cdot 6$ & $29 \cdot 5$ & $35 \cdot 2$ \\
\hline \multicolumn{6}{|l|}{ Energy by group } \\
\hline Baked goods and cereals & $20 \cdot 7$ & $20 \cdot 7$ & $20 \cdot 9$ & $19 \cdot 2$ & $20 \cdot 1$ \\
\hline Dressings/sauces/spreads & $4 \cdot 7$ & $7 \cdot 1$ & $6 \cdot 1$ & $4 \cdot 7$ & $5 \cdot 3$ \\
\hline High-sugar drinks including soft drinks & $16 \cdot 7$ & $12 \cdot 3$ & $14 \cdot 6$ & $5 \cdot 1$ & $14 \cdot 8$ \\
\hline Snack foodst & $14 \cdot 9$ & $11 \cdot 5$ & $12 \cdot 3$ & $11 \cdot 2$ & $11 \cdot 8$ \\
\hline \multicolumn{6}{|l|}{ Consuming high-fat food groups } \\
\hline Baked goods & $9 \cdot 6$ & $7 \cdot 0^{*}$ & $17 \cdot 2$ & $8 \cdot 2$ & $12 \cdot 8$ \\
\hline Fast/mixed foods & $22 \cdot 1$ & $29 \cdot 8$ & $25 \cdot 0$ & $26 \cdot 3$ & $25 \cdot 6$ \\
\hline Meat/fish & $42 \cdot 6$ & $49 \cdot 1$ & $45 \cdot 3$ & $45 \cdot 9$ & $45 \cdot 6$ \\
\hline Snack foodst & $44 \cdot 1$ & $31 \cdot 6$ & $40 \cdot 6$ & $36 \cdot 1$ & $38 \cdot 4$ \\
\hline \multicolumn{6}{|l|}{ Energy by group } \\
\hline Baked goods & $12 \cdot 2$ & $14 \cdot 9$ & $12 \cdot 8$ & $12 \cdot 9$ & $12 \cdot 8$ \\
\hline Fast/mixed foods & $26 \cdot 0$ & $29 \cdot 7$ & $31 \cdot 3$ & $24 \cdot 7$ & $28 \cdot 0$ \\
\hline Meat/fish & $21 \cdot 2$ & $14 \cdot 8$ & $15 \cdot 6$ & $20 \cdot 6$ & $18 \cdot 1$ \\
\hline Snack foodst & $17 \cdot \overline{6}$ & $17 \cdot 0$ & $17 \cdot 7$ & $17 \cdot 1$ & $17 \cdot 4$ \\
\hline
\end{tabular}

Wilcoxon signed-rank test for non-parametric variables; $\chi^{2}$ tests for differences in proportions.

${ }^{\star} P \leq 0.05,{ }^{\star *} P \leq 0.01$ significant differences by age noted.

tSnack foods included granola bars and other energy bars, chips, crisps, cheese puffs, nacho chips, fries and other deep-fried snacks and popcorn.

Table 4 Past day food group daily servings relative to Canada's Food Guide for First Nations, Inuit and Métis people, Cree youth of three communities (2005-2007)

\begin{tabular}{|c|c|c|c|c|c|c|c|c|c|c|c|c|c|}
\hline & \multicolumn{13}{|c|}{ Age category } \\
\hline & \multicolumn{6}{|c|}{ Children (9-13 years) } & \multicolumn{6}{|c|}{ Adolescents (14-18 years) } & \multirow{3}{*}{$\begin{array}{c}\text { Percentage } \\
\text { below } \\
\text { Rec. }\end{array}$} \\
\hline & \multicolumn{3}{|c|}{ Boys ( $n$ 30) } & \multicolumn{3}{|c|}{ Girls ( $n$ 38) } & \multicolumn{3}{|c|}{ Boys ( $n$ 31) } & \multicolumn{3}{|c|}{ Girls $(n 26)$} & \\
\hline & Mean & SD & Rec. & Mean & SD & Rec. & Mean & SD & Rec. & Mean & SD & Rec. & \\
\hline Vegetables and fruit & $2 \cdot 95$ & $3 \cdot 17$ & $5-6$ & $2 \cdot 65$ & $2 \cdot 81$ & $5-6$ & $4 \cdot 65$ & $4 \cdot 51$ & $7-10$ & $2 \cdot 67$ & $2 \cdot 86$ & $7-8$ & $63 \cdot 2$ \\
\hline Grain & $5 \cdot 77$ & 3.08 & $4-6$ & $5 \cdot 39$ & $3 \cdot 25$ & $4-6$ & $6 \cdot 14$ & $4 \cdot 46$ & $7-8$ & $4 \cdot 36$ & $2 \cdot 39$ & $6-7$ & $80 \cdot 8$ \\
\hline Milk products & $1 \cdot 31$ & $1 \cdot 40$ & $2-4$ & $1 \cdot 83$ & $2 \cdot 72$ & $2-4$ & $1 \cdot 63$ & $2 \cdot 07$ & $3-4$ & 1.05 & $0 \cdot 84$ & $3-4$ & $95 \cdot 1$ \\
\hline Meat and alternatives & $3 \cdot 22$ & $2 \cdot 59$ & $1-2$ & $2 \cdot 24$ & $2 \cdot 43$ & $1-2$ & $3 \cdot 57$ & $3 \cdot 15$ & 3 & $2 \cdot 18$ & $2 \cdot 19$ & 2 & $32 \cdot 0$ \\
\hline
\end{tabular}

Rec., recommended number of servings from Canada's Food Guide for First Nations, Inuit and Métis.

Health Canada (2007) 'Revision of Canada's Food Guide: Development of Food Intake Patterns'.

percentage $(20 \%)$ of total EI followed by $15 \%$ and $12 \%$ for the 'high-sugar drinks' and the 'snack foods' groups, respectively, for consumers of those items (Table 3).

For high-fat food groups, 9-13-year-olds were observed to consume a higher proportion of baked goods and cereals than the 14-18-year-olds (Table 3). Snack foods were consumed by $38 \%$ of the participants, accounting for $17 \%$ of the total daily energy for consumers. The meat and fish groups, consisting of different cuts of meat, birds and fish including bacon and sausages, were consumed by nearly $45 \%$ of the youth, accounting for $18 \%$ of their total daily EI.

A total of $63 \%$ of youth consumed fewer servings of vegetables and fruit and $95 \%$ of youth consumed less milk and alternatives than recommended by Canada's Food Guide for First Nations, Inuit and Métis (Table 4). Only $19 \%$ of the children met the recommended intake for grain products. Finally, $68 \%$ of youth exceeded the recommendations for meat and alternatives.

The traditional FFQ data indicated that consumption of TF when evaluated as d/month was low. Among the most popular items were meat (moose, caribou), fish (walleye, pike) and fowl (geese, ptarmigan; Table 5). Moose meat was the most common TF item eaten, consumed by $84 \%$ over the past year with youth reporting the consumption of moose meat an average of $2 \cdot 2 \mathrm{~d}$ /month. When TF items were combined into groups, almost all the participants $(83 \cdot 2 \%)$ consumed any fish $<0.5$ times/week and $65.6 \%$ of the youth consumed any traditional meat $<0.5$ times/week (Table 6). Nearly half of the youth consumed at least one kind of TF on a weekly basis.

Youth who were weekly consumers of TF were similar to those who were infrequent consumers in terms of total energy and macronutrient intake from the $24 \mathrm{~h}$ recall. 
Table 5 Percentage of youth consuming each TF item in the past year and frequency of consumption among consumers (d/month): Cree youth of three communities (2005-2007)

\begin{tabular}{lcc}
\hline & \multicolumn{2}{c}{ Youth } \\
\cline { 2 - 3 } Food & $\begin{array}{c}\text { Consumption in the } \\
\text { past year (\%) }\end{array}$ & $\mathrm{d} /$ month \\
\hline Meats & & \\
Moose meat & $84 \cdot 0$ & $2 \cdot 24$ \\
Caribou meat & $56 \cdot 8$ & $1 \cdot 68$ \\
Beaver meat & $52 \cdot 8$ & $0 \cdot 80$ \\
Rabbit meat & $52 \cdot 0$ & $0 \cdot 82$ \\
Bear meat & $44 \cdot 0$ & $0 \cdot 45$ \\
Speckled trout & $29 \cdot 6$ & $1 \cdot 09$ \\
Smoked game animal & $13 \cdot 6$ & $0 \cdot 52$ \\
Moose liver or kidney & $13 \cdot 6$ & $0 \cdot 47$ \\
Fish & & \\
Walleye & $42 \cdot 4$ & $1 \cdot 08$ \\
Pike & $28 \cdot 8$ & $0 \cdot 82$ \\
Smoked wild fish & $24 \cdot 8$ & $0 \cdot 67$ \\
Lake trout & $23 \cdot 2$ & $0 \cdot 87$ \\
Sturgeon & $11 \cdot 2$ & $0 \cdot 22$ \\
Whitefish & $9 \cdot 6$ & $0 \cdot 69$ \\
Red or white sucker & $9 \cdot 6$ & $1 \cdot 27$ \\
Fowls & & \\
Geese & $97 \cdot 6$ & $1 \cdot 72$ \\
Ptarmigan, partridge and & $63 \cdot 2$ & $1 \cdot 27$ \\
$\quad$ other birds & & \\
Goose gizzard & $26 \cdot 4$ & $1 \cdot 57$ \\
Dapplers & $24 \cdot 8$ & $0 \cdot 77$ \\
Sea ducks & $12 \cdot 0$ & $0 \cdot 80$ \\
Other TF & & \\
Wild berries & $57 \cdot 6$ & $1 \cdot 37$ \\
Wild berry jam & $55 \cdot 2$ & $1 \cdot 27$ \\
Goose grease & $48 \cdot 8$ & $0 \cdot 74$ \\
Bear grease & $15 \cdot 2$ & \\
\hline
\end{tabular}

TF, traditional food.

Foods included in the table are the ones with more than nine individuals consuming them in the past year.

Table 6 Percentage of consumed TF by frequency of consumption per week, Cree youth of three communities (2005-2007)

\begin{tabular}{lrrrrrr}
\hline & \multicolumn{5}{c}{ Frequency of consumption per week } \\
\cline { 2 - 7 } Type & $0-0.5$ & $0.5<1$ & $1-2$ & $2-3$ & $3-4$ & $>4$ \\
\hline Meats (\%) & 65.6 & 12.0 & 10.4 & 2.4 & 3.2 & 6.4 \\
Fish (\%) & 83.2 & 7.2 & 4.0 & 0.8 & 1.6 & 3.2 \\
Fowl (\%) & 60.8 & 21.6 & 8.8 & 4.0 & 0.8 & 4.0 \\
Any TF (\%) & 25.0 & 21.0 & 22.6 & 10.5 & 3.2 & $17 \cdot 7$ \\
\hline
\end{tabular}

$\mathrm{TF}$, traditional food.

However, youth consuming TF at least once weekly were observed to have a significantly lower mean BMI percentile than those consuming TF infrequently $(80 \cdot 1$ (SD 24.6) $v .87 \cdot 3$ (SD 14.8), $P \leq 0 \cdot 05$ ). However, there were no significant differences in WC and body fat by level of TF consumption. Weekly fruit and vegetable intake from the market FFQ was also significantly higher when TF was consumed at least once weekly $(12 \cdot 1$ (SD 8.8) v. 9.2 (SD $7 \cdot 4), P \leq 0 \cdot 05)$. However, youth with weekly TF consumption also had a higher consumption of snacks with fat and oil (chips, nachos, popcorn and French fries), with $17 \cdot 1$ (SD 7·7) v. $13 \cdot 4$ ( $\mathrm{SD} 7 \cdot 6)$ servings/week $(P \leq 0 \cdot 01)$. High-sugar foods and groups from the market FFQ were not significantly different from TF intake groups. The Canadian HEI scores were significantly higher among those who consumed TF at least once weekly than among those consuming TF less frequently (64·1 (SD 7•6) $v \cdot 60 \cdot 4$ (sD $8 \cdot 1), P \leq 0 \cdot 05)$.

Youth who consumed less than one fruit or vegetable serving a day had a $34 \%$ higher risk of having an at-risk WC than youth consuming fruit or vegetables more frequently (relative risk $=1 \cdot 34 ; 95 \%$ CI $1 \cdot 05,1 \cdot 71$ ). The Canadian HEI scores were significantly lower among those with an at-risk WC than among those with a normal WC (61.2 (sD 7.9) v. $64 \cdot 7$ (SD 7.5), $P \leq 0 \cdot 05)$. However, there were no individual food groups differences and no significant differences in the Canadian HEI scores between those with a normal BMI and those at risk for overweight or overweight (HEI 63.8 (SD 7·9) v. $61 \cdot 6(\mathrm{SD} 7 \cdot 8), P \leq 0 \cdot 10)$.

\section{Discussion}

In summary, the food frequency method in combination with the $24 \mathrm{~h}$ recall provided a means of determining prevalent dietary patterns among the youth. Moreover, anthropometry was directly measured in contrast to the self-reported data presented earlier ${ }^{(10)}$. The prevalence of overweight and overall poor dietary quality is a public health concern in the three communities. The high proportion of at risk for overweight and overweight youth in the present study is similar to previous studies conducted among the Cree ${ }^{(10,13)}$ and similar to other studies indicating a high prevalence of overweight among indigenous youth $^{(23,24)}$. The prevalence of overweight in this study population is four to five times higher than that of the general Canadian population of similarly aged children ${ }^{(25)}$.

The study found a high degree of consumption of highsugar and high-fat food items, low fruit and vegetable and milk product intake coupled with low TF consumption, and a low HEI, with 95\% falling below the recommended healthy score of 80 or above. The nutrition transition includes a shift away from hunting, harvesting and consumption of TF towards a more sedentary lifestyle and a market-based diet rich in carbohydrates, fat and saturated $\mathrm{fat}^{(26)}$. Developing healthy eating patterns early in life is a challenge due to the socio-economic context of food availability and choices. As $70 \%$ of overweight children tend to become obese adults ${ }^{(27)}$, it is important to redirect children towards healthier food choices. Poor dietary habits together with low physical activity among children observed in previous Cree studies ${ }^{(28,29)}$ help explain the high prevalence of overweight.

Sugar was found to be the most commonly mentioned market food in the $24 \mathrm{~h}$ recalls of adults from the Canadian Arctic $^{(30)}$. In particular, sweets contributed to $20 \%$ of the EI in Dene/Métis and Yukon children's diet ${ }^{(7)}$. In addition, these drinks contributed to a displacement of food considered as primary sources of nutrients such as milk, fruit 
and vegetables ${ }^{(31)}$. Several studies of children and adolescents have found a significant association between sugar-sweetened beverage intake and overweight ${ }^{(32,33)}$, suggesting that the high sugar consumption places Cree youth at risk.

The present study was one of the first to present consumption of high-sugar and high-fat foods from specific food categories in order to understand their contribution to total EI. In summary, energy-dense foods were found to contribute an important percentage of EI among Cree youth, thus raising concerns that they may displace higher-quality nutrient-dense food items in the diet. The excessive intake of high-sugar and high-fat foods was previously observed in a Dene/Métis study, where the use of fat and sugar-rich foods contributed to more than $40 \%$ of energy $^{(7)}$. Similarly, in the present study, over half of the total EI was derived from fat, sweets, mixed dishes and other high-energy items.

The low consumption of vegetables and fruit and milk and alternatives indicates a potential for low intakes of calcium and other vital nutrients. In a previous study conducted among the same population 15 years ago in $1993^{(10)}$, the diet of 9-11-year-old Cree children met or exceeded the mean number of servings recommended for the food groups, while the older youth ( $\geq 12$ years) had low intake of milk/milk products and vegetables/fruit. The findings were attributed to the positive impact of community programmes among the youngest group, such as the school milk programme. In addition, the percentage of at risk/overweight youth in the study 15 years ago was lower (38\%) than that observed in the present study. The increase in overweight and poor dietary behaviours suggests an ongoing nutrition and epidemiological transition among Cree with serious future health consequences for youth. These findings further stress the need to implement interventions.

TF food use was higher among Dene/Métis children ${ }^{(7)}$ than in the current Cree population. Higher TF use among communities situated further north was previously noted in the literature ${ }^{(5)}$. The relatively low TF use by Cree children and adolescents is similar to that found in other study populations showing that children are consuming less TF than adults ${ }^{(5,7,11)}$. In the three territories of Canada, TF contributed to increased intake of essential nutrients. When comparing days with and without TF, TF intake was found to be associated with higher consumption of vitamins $\mathrm{D}, \mathrm{E}, \mathrm{B}_{6}$, riboflavin, iron and other important nutrients ${ }^{(5,7,30)}$. Furthermore, TF use, even at levels as low as 5\% of energy, contributed to a higher intake of several essential nutrients among children ${ }^{(7)}$.

The present results, indicating no differences in terms of EI and macronutrients between the low and high TFconsuming groups, are in contrast with data from Dene/ Métis adults, where days without TF were associated with higher EI, carbohydrate, fat and saturated fat intake than days with $\mathrm{TF}^{(5)}$. TF systems and the context in which they are consumed are diverse. Among the Arctic Indigenous people, days with TF were associated with significantly higher total energy $(P \leq 0 \cdot 01)$ and percentage of energy from protein than days without $\mathrm{TF}^{(30)}$. Among Cree youth, TF consumption was associated with significantly greater weekly vegetable and fruit consumption, and a significantly lower BMI, but a higher number of snacks. TF is often consumed in community or family celebrations or out on the land where high-fat snack foods may be served. Speculations regarding the relationship of weekly TF consumption with lower BMI include the potential for a higher level of physical activity among weekly TF consumers ${ }^{(26)}$ relative to less frequent TF consumers; however, this cannot be directly assessed in the present study. Furthermore, vegetable and fruit consumption was related to a lower risk of having an at-risk WC, potentially reflecting that vegetables and fruit may be displacing snacks high in added sugar and fat or that vegetable and fruit consumption may be a marker for other healthy habits. Furthermore, overall diet quality as measured by HEI was lower among those with an at-risk WC.

\section{Under-reporting of energy intake}

Overall, the mean EI:BMR ratio in the present study population was 1.31 (SD 0.62 ), indicating a suboptimal reporting of EI. However, when under-reporting was further evaluated among youth categorised into BMI percentile groups, under-reporting was observed only among overweight youth (those with normal BMI had an acceptable EI:BMR ratio of 1.56 ). The under-reporting of EI among overweight Cree youth is supported by several studies, which found evidence of under-reporting of EI by higher weight children and adults ${ }^{(34,35)}$. Many factors may occur in late childhood and adolescents that would contribute to the underreporting of EI among higher-weight individuals ${ }^{(36,37)}$. Another issue related to heavier children is that their BMR may be overestimated based upon having a greater adipose tissue mass; however, overestimates are very likely not large based upon a review of the available literature ${ }^{(19)}$.

Similar to other studies involving children in Canada, the United States and Europe, total EI was greater for boys than for girls in the present study ${ }^{(38-40)}$. The lack of differences in EI by age group could be partially explained by the greater under-reporting in the 14-18-year-olds (EI:BMR $=1 \cdot 2$ ( $\mathrm{SD}$ $0 \cdot 6)$ than in the younger children $(\mathrm{EI}: \mathrm{BMR}=1 \cdot 4(\mathrm{SD} 0 \cdot 6)$. Similarly, Livingstone et al. $^{(39)}$ found a divergence between the reported EI and total energy expenditure measured by doubly labelled water as age increased.

When compared with dietary studies of similarly aged youth conducted in indigenous communities, the reported EI of Cree youth was similar to that of Mohawk $(8991 \cdot 4 \mathrm{~kJ})^{(41)}$ and of children (8-15 years) in northern Alberta with reported mean EI of $8633.3 \mathrm{~kJ}$ and $7367 \cdot 6 \mathrm{~kJ}$ for boys and girls, respectively ${ }^{(42)}$. Thus, the similarities in EI between 9-13- and 14-18-year-olds were unexpected, but may partly be due to the higher under-reporting of EI 
among adolescents. Importantly, results were similar when run with and without the under-reporters of EI.

\section{Limitations}

Although repeated dietary assessment are always better for characterising habitual diet, the use of one $24 \mathrm{~h}$ recall is useful for evaluating diet at a population level. However, the small sample size with one $24 \mathrm{~h}$ dietary assessment in the subanalyses comparing those with and without a normal BMI is a limitation as repeated dietary assessments for small groups would have very likely revealed greater dietary differences by BMI category. Furthermore, the present study utilised existing cut-offs for determining adiposity from available referent populations, which may not be generalisable to the Cree. Another limitation is that the Canadian Nutrient File is incomplete for sugar. This limitation, combined with under-reporting, very likely means that participants may be consuming even higher intakes of sugar than described herein.

\section{Summary}

The present study adds to the limited literature on diet quality among high-risk indigenous youth. The study contributes to the literature in that it found that poor dietary quality was highly prevalent and that diet quality was related to central fat patterning among Cree youth, whereas TF consumption was related to a lower BMI. The study indicates that interventions are urgently needed. Strategies that encourage a healthy diet including the incorporation of $\mathrm{TF}$ in the diet may represent a culturally acceptable means of promoting a healthy future for Cree youth.

\section{Acknowledgements}

The present study was funded by the Niskamoon Corporation (a non-profit organisation funded by HydroQuébec). The authors declared no conflict of interest. The authors thank the Nituuchischaayihtitaau Aschii Steering committee, Suzanne Cote for managing all field work, and the data collection team including interviewers from the communities of Mistissini, Eastmain and Weminji. G.M.E. helped and designed the study and supervised all aspects of analyses, and report writing, guided interpretation of the data and edited the final text. L.J.-D. trained the field staff, supervised the data entry and dietary quality assessment and helped in data analyses. C.B.K. supervised the dietary assessments in the field, analysed the data and wrote the draft paper. All co-authors made substantial contributions to the final editing, interpretation and writing of the paper.

\section{References}

1. Tjepkema M (2006) Adult obesity. Health Rep 17, 9-25.

2. Dehghan M, Akhtar-Danesh N \& Merchant AT (2005) Childhood obesity, prevalence and prevention. Nutr J4, 24.
3. Sachdev HS, Osmond C, Fall C et al. (2009) Predicting adult metabolic syndrome from childhood body mass index: follow-up of the New Delhi birth cohort. Arch Dis Child 94, 768-774.

4. Shields M (2006) Overweight and obesity among children and youth. Health Rep 17, 27-42.

5. Receveur O, Boulay M \& Kuhnlein HV (1997) Decreasing traditional food use affects diet quality for adult Dene/Metis in 16 communities of the Canadian Northwest Territories. J Nutr 127, 2179-2186.

6. Egeland GM, Berti P, Soueida R et al. (2004) Age differences in vitamin A intake among Canadian Inuit. Can J Public Health 95, 465-469.

7. Nakano T, Fediuk K, Kassi N et al. (2005) Food use of Dene/Metis and Yukon children. Int J Circumpolar Health 64, 137-146.

8. Blanchet C, Dewailly E, Ayotte P et al. (2000) Contribution of selected traditional and market foods to the diet of Nunavik Inuit women. Can J Diet Pract Res 61, 50-59.

9. Nakano T, Fediuk K, Kassi N et al. (2005) Dietary nutrients and anthropometry of Dene/Metis and Yukon children. Int J Circumpolar Health 64, 147-156.

10. Bernard L, Lavallee C, Gray-Donald K et al. (1995) Overweight in Cree schoolchildren and adolescents associated with diet, low physical activity, and high television viewing. J Am Diet Assoc 95, 800-802.

11. Murphy NJ, Schraer CD, Thiele MC et al. (1995) Dietary change and obesity associated with glucose intolerance in Alaska Natives. J Am Diet Assoc 95, 676-682.

12. Gittelsohn J, Wolever TM, Harris SB et al. (1998) Specific patterns of food consumption and preparation are associated with diabetes and obesity in a Native Canadian community. J Nutr 128, 541-547.

13. Torrie J, Bobet E, Kishchuk N et al. (2005) The Evolution of Health Status and Health Determinants in the Cree Region (Eeyou Istchee) Eastmain 1-A Powerbouse and Rupert Diversion Sectoral Report. 1. Montréal, Québec: Cree Board of Health and Social Services.

14. MacMillan HL, MacMillan AB, Offord DR et al. (1996) Aboriginal health. CMAJ 155, 1569-1578.

15. Shatenstein B (2005) Canadian healthy eating index. $J$ Am Diet Assoc 105, 1251-1260.

16. Roberts SB \& Dallal GE (2001) The new childhood growth charts. Nutr Rev 59, 31-36.

17. Fernandez JR, Redden DT, Pietrobelli A et al. (2004) Waist circumference percentiles in nationally representative samples of African-American, European-American, and Mexican-American children and adolescents. I Pediatr 145, 439-444.

18. McCarthy HD, Cole TJ, Fry $\mathrm{T}$ et al. (2006) Body fat reference curves for children. Int J Obes 30, 598-602.

19. World Health Organization (1985) Energy and Protein Requirements. Joint WHO/FAO Expert Consultation. WHO Technical Report Series no. 24. Geneva: WHO.

20. Goldberg GR, Black AE, Jebb SA et al. (1991) Critical evaluation of energy intake data using fundamental principles of energy physiology: 1. Derivation of cut-off limits to identify under-recording. Eur J Clin Nutr $\mathbf{4 5}$, 569-581.

21. Black AE, Goldberg GR, Jebb SA et al. (1991) Critical evaluation of energy intake data using fundamental principles of energy physiology: 2. Evaluating the results of published surveys. Eur J Clin Nutr 45, 583-599.

22. Institute of Medicine, Food and Nutrition Board (2005) Dietary Reference Intakes. Washington, DC: National Academy Press.

23. Vanasse A, Demers M, Hemiari A et al. (2006) Obesity in Canada: where and how many? Int J Obes 30, 677-683.

24. Young TK, Dean HJ, Flett B et al. (2000) Childhood obesity in a population at high risk for type 2 diabetes. J Pediatr 136, 365-369. 
25. Belanger-Ducharme F \& Tremblay A (2005) Prevalence of obesity in Canada. Obes Rev 6, 183-186.

26. Kuhnlein HV \& Receveur O (1996) Dietary change and traditional food systems of indigenous peoples. Annu Rev Nutr 6, 417-442.

27. Cheng TO (2007) Fat kids grow up to be fat adults: a lesson to be learned from China. Int J Cardiol 117, 133-135.

28. Ng C, Marshall D \& Willows ND (2006) Obesity, adiposity, physical fitness and activity levels in Cree children. Int J Circumpolar Health 65, 322-330.

29. Downs SM, Marshall D, Ng C et al. (2008) Central adiposity and associated lifestyle factors in Cree children. $A p p l$ Physiol Nutr Metab 33, 476-482.

30. Kuhnlein HV, Receveur O, Soueida R et al. (2004) Arctic indigenous peoples experience the nutrition transition with changing dietary patterns and obesity. J Nutr 134, $1447-1453$.

31. French SA, Lin BH \& Guthrie JF (2003) National trends in soft drink consumption among children and adolescents age 6 to 17 years: prevalence, amounts, and sources, 1977/ 1978 to 1994/1998. J Am Diet Assoc 103, 1326-1331.

32. Sanigorski AM, Bell AC \& Swinburn BA (2007) Association of key foods and beverages with obesity in Australian schoolchildren. Public Health Nutr 10, 152-157.

33. Giammattei J, Blix G, Marshak HH et al. (2003) Television watching and soft drink consumption: associations with obesity in 11- to 13-year-old schoolchildren. Arch Pediatr Adolesc Med 57, 882-886.

34. McGloin AF, Livingstone MB, Greene LC et al. (2002) Energy and fat intake in obese and lean children at varying risk of obesity. Int J Obes Relat Metab Disord 26, 200-207.

35. Baxter SD, Smith AF, Nichols MD et al. (2006) Children's dietary reporting accuracy over multiple 24-hour recalls varies by body mass index category. Nutr Res 26, 241-248.

36. Fisher JO, Johnson RK, Lindquist C et al. (2000) Influence of body composition on the accuracy of reported energy intake in children. Obes Res 8, 597-603.

37. Scagliusi FB, Polacow VO, Artioli GG et al. (2003) Selective under-reporting of energy intake in women: magnitude, determinants, and effect of training. J Am Diet Assoc 103, $1306-1313$.

38. Troiano RP, Briefel RR, Carroll MD et al. (2000) Energy and fat intakes of children and adolescents in the United States: data from the National Health and Nutrition Examination Surveys. Am J Clin Nutr 72, Suppl. 5, 1343S-1353S.

39. Livingstone MB, Prentice AM, Coward WA et al. (1992) Validation of estimates of energy intake by weighed dietary record and diet history in children and adolescents. Am J Clin Nutr 56, 29-35.

40. Guillaume M, Lapidus L \& Lambert A (1998) Obesity and nutrition in children. The Belgian Luxembourg Child Study IV. Eur J Clin Nutr 52, 323-328.

41. Jimenez MM, Receveur O, Trifinopoulos M et al. (2003) Comparison of the dietary intakes of 2 different groups of children grades 4 to 6 before and after Kahnawake Schools Diabetes Prevention Project. J Am Diet Assoc 103, 1191-1194.

42. Wein E, Gee M \& Hawrysh Z (1993) Nutrient intakes of native mothers and school children in northern Alberta. Can J Diet Pract Res 54, 42-47. 